\title{
INFLUENCE OF LIMING ON KINETICS OF SEWAGE SLUDGE PYROLYSIS
}

\author{
WPŁYW WAPNOWANIA OSADÓW ŚCIEKOWYCH \\ NA KINETYKĘ ICH PIROLIZY
}

\begin{abstract}
Thermogravimetry (TG) is the fast and reliable method for characterization of thermal decomposition of any material and in particular to determine the kinetics of pyrolytic decomposition of sewage sludge. Two types of sewage sludge with and without addition of lime were investigated from kinetic point of view. For TG analysis samples of selected sewage sludge were heated under the inert atmosphere of argon with constant heating rate from 303 to $1273 \mathrm{~K}$; the three heating rate $\beta=5,10$ and $20 \mathrm{~K} / \mathrm{min}$ were chosen. The iso-conversion methods of Friedman and Ozawa-Flynn-Wall were employed for analysis of TG results. As the sewage sludge decomposition is very complex process it cannot be described by a simple stoichiometric equation, therefore the so called lumping of reactions in the selected temperature ranges were used with detailed principles arising from visual analysis of DTG curve. The deconvolution of DTG curves performed according to Fraser-Suzuki asymmetric profile allowed the identification of number of lumps and their contribution to the overall mass loss. So the decomposition of sewage sludge with lime addition could be described with five groups of reactions while the one without lime by means of six lumps. The thermal decomposition of sewage sludge was assumed to proceed according to the scheme of parallel concurrent independent reactions of $n$-th order. The values of the apparent activation energies at different constant values of conversion degrees were determined by the iso-conversion analysis. To estimate the kinetic parameters the non-linear regression with Levenberg-Marquart optimization procedure was used. The kinetic parameters such as activation energy, pre-exponential factor, reaction order and fraction of total mass loss associated with a given reaction were determined. The impact of sewage sludge liming revealed in essential differences of pyrolysis products and pyrolysis kinetics of limed sludge and without lime one was highlighted.
\end{abstract}

Keywords: pyrolysis, sewage sludge, thermogravimetry, TGA

\section{Introduction}

One of the method of sewage sludge (SS) disposal is thermal conversion, such as pyrolysis, gasification, or combustion. According to recent assessment of Samolada and Zabaniotou, by application of SWOT analysis to thermal treatment of SS by these processes an optimal thermo-chemical treatment option seems to be pyrolysis [1]. This alternative not only enables the removal of organic pollutants and pathogenic organisms, but allows for the recovery of the SS energy. The pyrolysis is a thermal degradation of organic matter in the

\footnotetext{
${ }^{1}$ Faculty of Process and Environmental Engineering, Lodz University of Technology, ul. Wólczańska 213, 90-924 Łódź, Poland, phone +48 426313715

*Corresponding author: stanleda@p.lodzł.pl
} 
absence of oxidizing agents, resulting in the production of three groups of products: permanent gases, a pyrolytic liquid (oil/tar) and char [2]. The products result from both primary decomposition of the solid matter and secondary reactions of volatile condensable organic products into low-molecular weight gases and char. Many factors can affect the pyrolysis rate and the yields and composition of the products. Temperature, and heating rate are the main operating parameters. In addition, sludge properties (chemical composition, ash content and its composition), particle size and shape, density, moisture content also play an important role [3].

One of the most widely used method of sludge hygienisation is liming. The SS liming brings the following benefits: a) conditioning all types of sludge, b) precipitation of toxic metals and removal of nutrients, c) destroying of the pathogenic agents, d) reduction of the biochemical and biological oxygen demand and suspended solids, e) elimination of odors. A usual dose of quicklime $(\mathrm{CaO})$ is ca. 10-20\% wt. of the dry matter of sludge [4]. Sometimes also slaked lime $\left(\mathrm{Ca}(\mathrm{OH})_{2}\right)$ is used [5]. However, after quicklime addition to the sludge, calcium oxide is transformed into $\mathrm{Ca}(\mathrm{OH})_{2}$. No significant difference has been observed between the effect of hydrated lime and quicklime when treating sludge with high water content. The addition of lime changes composition of SS and also can influence the kinetic behavior of SS during its thermal treatment. Cízkova et al. [4] studied pyrolysis of sludge without liming and limed sludge. Their results of laboratory pyrolysis proved that limed sludge released the maximum amount of carbon - $55.4 \%$, while sludge without liming released only $48.9 \%$. Calcite produces during decomposition $\mathrm{CaO}$ and the product influences the pyrolysis process because it supports cracking of volatile organic compounds. Calcium based compounds also reduce pollutants (mainly $\mathrm{HCN}, \mathrm{NH}_{3}$ and $\mathrm{H}_{2} \mathrm{~S}$ ) during sludge pyrolysis $[6,7]$.

There are many research works on kinetics of SS pyrolysis usually by thermogravimetry alone or thermogravimetry coupled with mass spectrometer (MS) or infrared spectrometry (FTIR) [8,9]. It is well known that mineral matter has been reported to catalyzes the thermo-chemical reactions $[10,11]$. Shao et al. [12] studied the catalytic effect of impregnated metal oxides $\left(\mathrm{Al}_{2} \mathrm{O}_{3}, \mathrm{CaO}, \mathrm{Fe}_{2} \mathrm{O}_{3}, \mathrm{TiO}_{2}\right.$, and $\left.\mathrm{ZnO}\right)$ on $\mathrm{SS}$ pyrolysis in a thermogravimetric analyzer, however the samples were acid-washed for reduction of the mineral matter. They found that all of the metal oxides studied promoted the initial decomposition of the sludge sample, while $\mathrm{CaO}$ may promote the initial decomposition of hemicellulose and further degradation of lignin, but inhibit the decomposition of cellulose in demineralized sludge sample. The kinetic calculations were carried out using equation based on assumption of a first-order reaction in the pyrolysis of SS. Quite recently Tang et al. [5] analyzed the effect of $\mathrm{Ca}(\mathrm{OH})_{2}$ on the pyrolysis of SS in terms of reaction characteristics and kinetics.

To the best of our knowledge very few research, except the mentioned above, was focused on the detailed kinetics of SS pyrolysis treated with lime, therefore the aim of this work is to determine the influence of liming on the kinetics of SS pyrolysis.

\section{Material and methods}

Two types of SS from Wastewater Treatment Plant "Prosna" in Kuchary near Kalisz, Poland were selected for this study: SS without liming and limed SS. Dewatered samples of limed SS of $75 \%$ wt. moisture content and that without liming (86\% wt. moisture) were dried at $378 \mathrm{~K}$ and homogenized. 
Experiments were performed in a Mettler-Toledo TGA/SDTA851 LF. The SS pyrolysis was carried out on sample of $30.0 \pm 0.1 \mathrm{mg}$ of dried SS. The samples of particle size below $40 \mu \mathrm{m}$ were placed into aluminum pans, of $100 \mathrm{~mm}^{3}$ volume, without lids and heated up from ambient temperature to $1273 \mathrm{~K}$ with a constant heating rate under inert atmosphere of argon gas flowing around the sample with the rate $150 \mathrm{~cm}^{3} / \mathrm{min}$. Three heating rate $\beta=5,10,20 \mathrm{~K} / \mathrm{min}$ were used. More details of experimental set-up and the experimental procedure can be found elsewhere [13].

\section{Results and discussion}

Figures 1 and 2 present the results of TG and DTG curves for the SS with and without lime respectively, taken at heating rate $\beta=5 \mathrm{~K} / \mathrm{min}$, while in Table 1 averaged mass balances for the three scans based on thermogravimetric measurements were shown.

Table 1

Mass losses during pyrolysis and char burning

\begin{tabular}{|c|c|c|c|c|}
\hline \multirow[t]{2}{*}{ Sample name } & $\begin{array}{c}\text { Mass loss after } \\
\text { pyrolysis }\end{array}$ & Char content & $\begin{array}{c}\text { Total mass loss } \\
\text { after char burning }\end{array}$ & Minerals content \\
\hline & \multicolumn{4}{|c|}{ [\% wt.] } \\
\hline SS without lime & 69.4 & 10.9 & 80.3 & 19.7 \\
\hline SS with lime & 54.2 & 1.7 & 55.9 & 44.1 \\
\hline
\end{tabular}

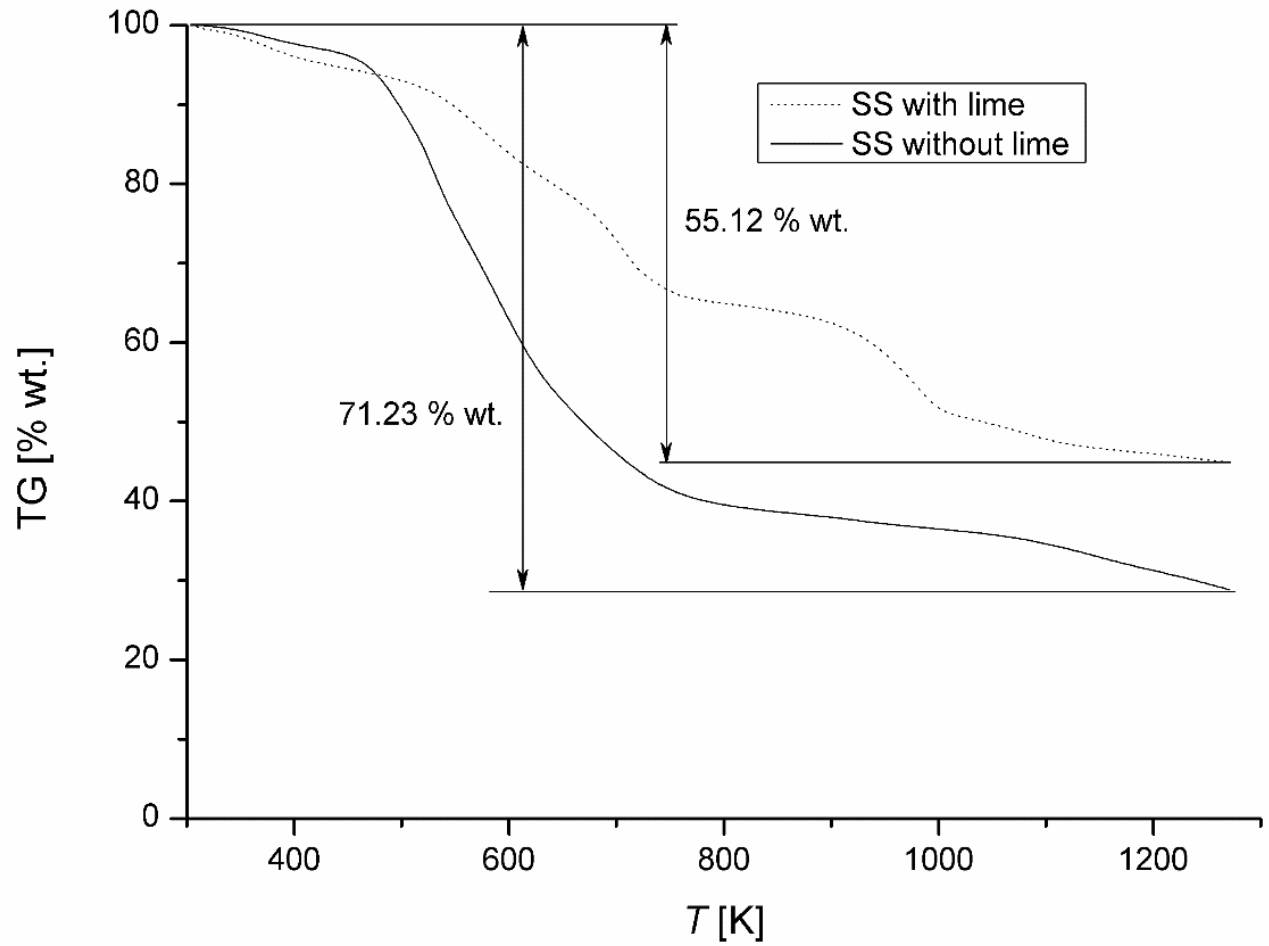

Fig. 1. Comparison of TG curves for the SS with and without lime 


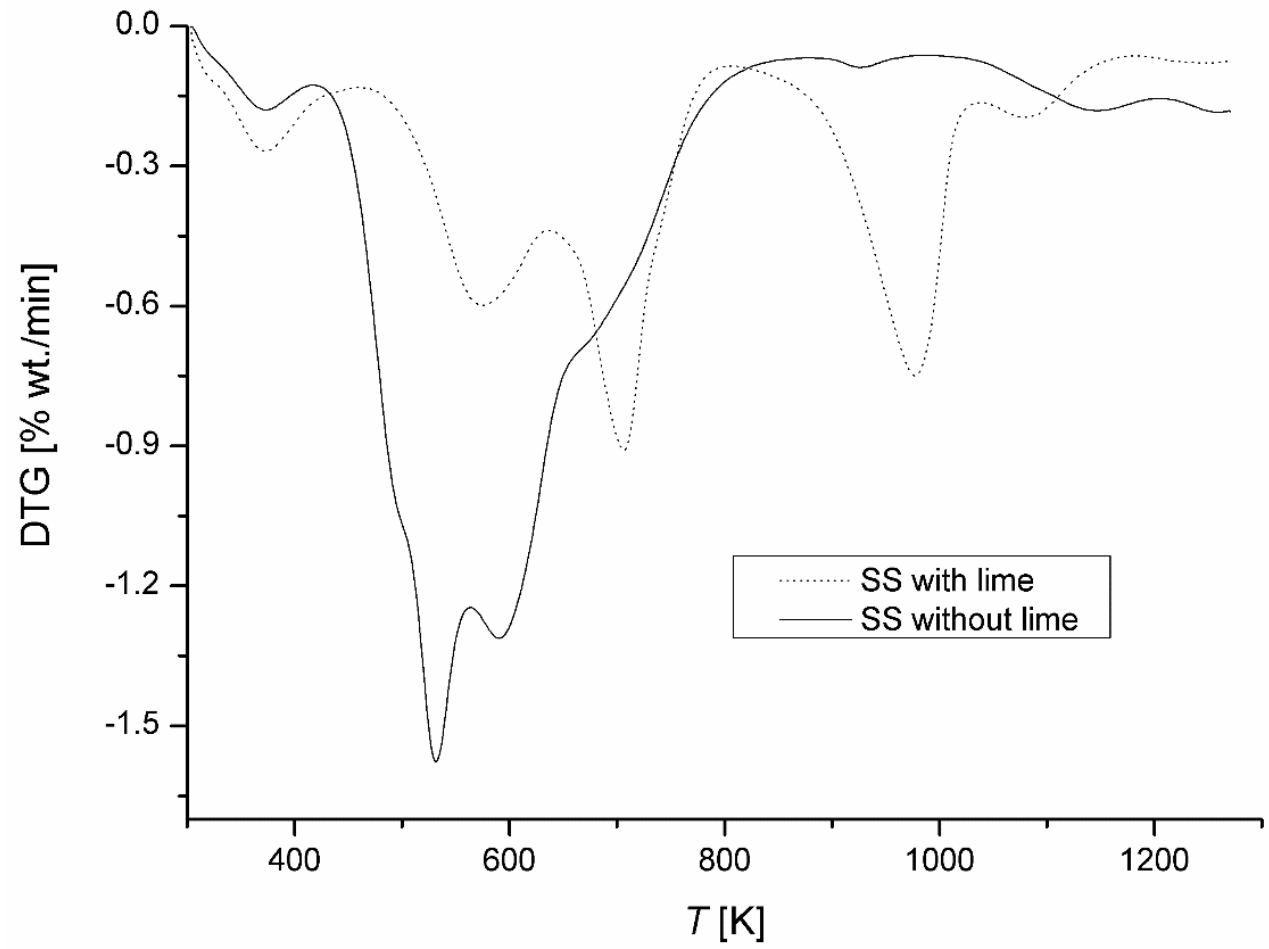

Fig. 2. Comparison of DTG curves for the SS with and without lime

As it is seen from TG curves the main processes of pyrolytic decomposition of the SS without liming proceed in the temperature range 473-873 K. The mass loss of the SS without lime during pyrolysis is bigger $(69.4 \%$ wt.) than for the SS with lime $(54.2 \%$ wt.) (Table 1). The DTG curves in Figure 2 visualize the rate of the processes occurring during the SS thermal decomposition. In case of the SS without lime the main peak is observed at $523 \mathrm{~K}$, while for the SS with lime the distinct peaks are at 553, 723 and $972 \mathrm{~K}$ and their shapes indicate that there are also other reactions occurred at the temperature range.

It is well known that for reliable estimation of kinetic parameters of any pyrolysis process under non-isothermal conditions needs minimum three heating rates. The pyrolysis process of SS is very complex - the decomposition of the SS can be described with the model involving many reactions. However, the stoichiometry of these reactions are unknown. Therefore in order to simplifying the kinetic description the reactions proceeding in the selected temperature ranges were grouped in the so called lumps arising from the analysis of DTG curves supported often by mass spectrometry [13-15]. To describe the rate of the SS pyrolysis it was assumed that according to previous findings the process proceeds via parallel co-current independent reactions expressed by differential equations of the following type (1):

$$
\frac{\mathrm{d} \alpha}{\mathrm{d} \tau}=k_{0} \cdot\left(-\frac{E}{\mathrm{R} \cdot T}\right) \cdot(1-\alpha)^{n}
$$


where $k_{0}$ stands for the pre-exponential factor [1/s], $E$ quantifies the energy of activation $[\mathrm{kJ} / \mathrm{mol}], \mathrm{R}$ is the universal gas constant $8.314 \mathrm{~J} /(\mathrm{mol} \cdot \mathrm{K}), n$ is the reaction order $[-], T$ is the furnace temperature $[\mathrm{K}], \tau$ is the time of pyrolysis $[\mathrm{s}]$ and $\alpha$ is the degree of conversion defined as $\alpha=\left(m_{0}-m_{\tau}\right) /\left(m_{0}-m_{f}\right) ; m_{0}$ is the initial mass of sample [g], $m_{\tau}$ is the mass at time $\tau$ [g], and $m_{f}$ is the final mass at the end of pyrolysis [g].

For each reaction (lump) three kinetic parameters should be estimated: $k_{0}, E, n$ and additionally the fraction of the given reaction in the total mass loss. Even for few reactions (lumps) it is necessary to estimated several model parameters by means of non-linear regression, but the values of evaluated parameters should in the accepted range. In order to find the minimum of the target function in the optimization procedure it is important to formulate the starting values of the parameters. Therefore, we applied the following sequence in estimation of the kinetic parameters:

- deconvolution of the DTG curves in to single peaks corresponding to the group of reactions by means of Netzsch Peak Separation program, due to which it was also possible to determine the fractions of the given reactions in the total mass loss,

- estimation of distribution of energy activation and pre-exponential factor as a function of $\alpha$ by employing the procedure of Friedman and Ozawa-Flynn-Wall,

- based on the results of the above procedures the starting parameters to the program Netzsch Kinetics was used for the final estimation of the kinetic parameters.

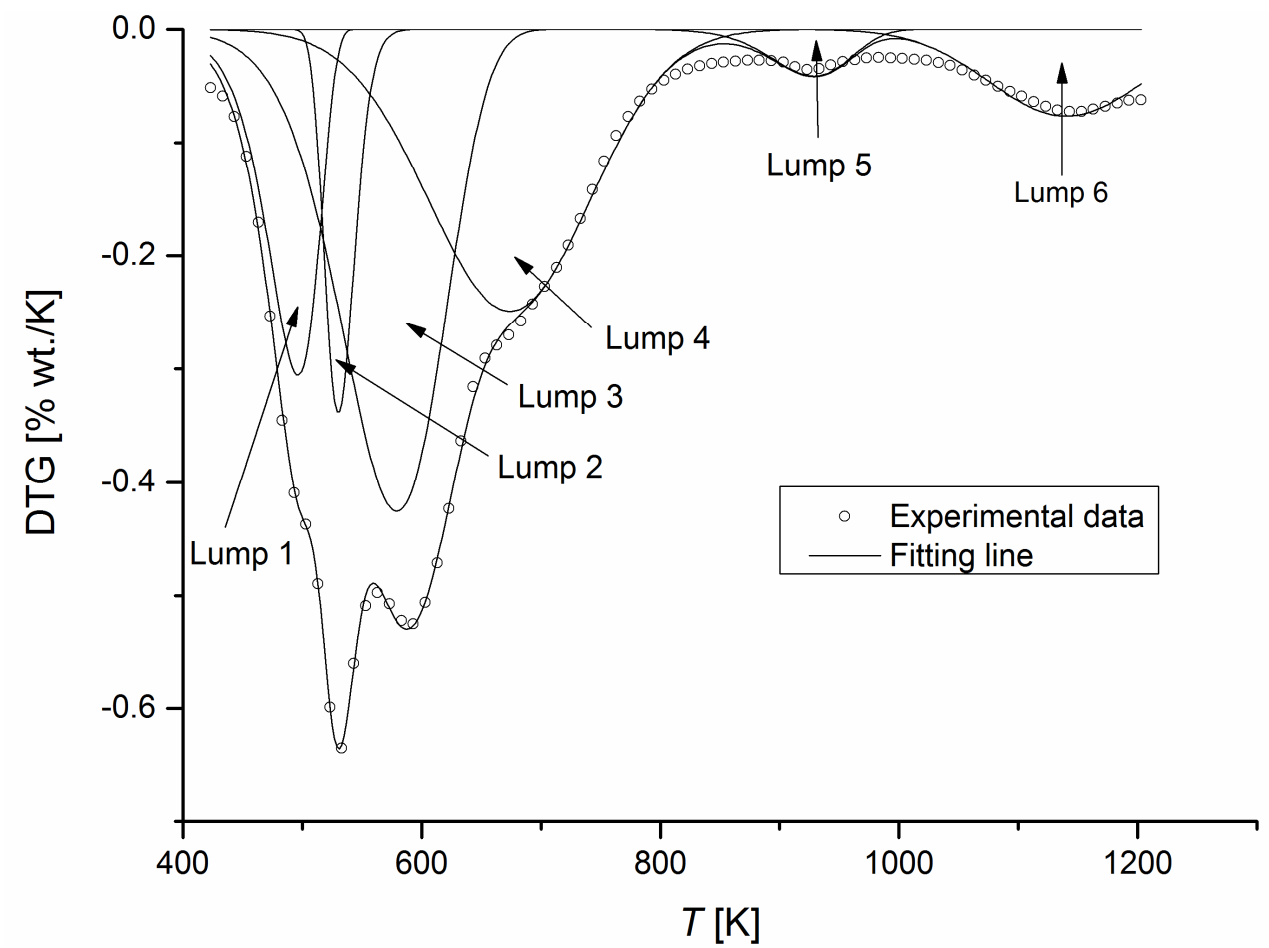

Fig. 3. Deconvolution of the DTG curve for the SS without liming 
The deconvolution according to Fraser-Suzuki asymmetric profile of DTG curves for the SS without liming and the SS with lime were shown in Figures 3 and 4 respectively. The choice of the number of peaks is quite subjective, however one should choose the minimum peaks that could properly reconstruct the shape of the DTG curve. So, in Figure 3 we have six peaks, while in Figure 4 only five peaks are sufficient. In Table 2 the parameters of the deconvolution for the SS without lime is presented as an example. Peaks above $673 \mathrm{~K}$ had a higher amplitude for SS with lime, which was caused by the decomposition of $\mathrm{Ca}(\mathrm{OH})_{2}$ and $\mathrm{CaCO}_{3}$ that catalyzed pyrolysis process similarly as in research by Tang et al. [5].

Table 1

Parameters of the deconvolution of the DTG curve for the SS without liming

\begin{tabular}{|c|c|c|c|c|c|c|}
\hline No. peak & $\mathbf{1}$ & $\mathbf{2}$ & $\mathbf{3}$ & $\mathbf{4}$ & $\mathbf{5}$ & $\mathbf{6}$ \\
\hline Type & Fraser-Suzuki & Fraser-Suzuki & Fraser-Suzuki & Fraser-Suzuki & Fraser-Suzuki & Fraser-Suzuki \\
\hline Area [\%] & 13.2 & 8.01 & 35.2 & 32.1 & 2.56 & 9.13 \\
\hline Position [K] & 496.7 & 530.4 & 579.0 & 674.5 & 928.7 & 1140.9 \\
\hline Amplitude [\% wt./K] & -0.306 & -0.339 & -0.426 & -0.249 & -0.0413 & -0.0769 \\
\hline Width [K] & 50.3 & 29.3 & 102.0 & 158.4 & 76.4 & 150.7 \\
\hline Asymmetry [-] & 0.40 & -0.16 & 0.18 & 0.013 & 0.18 & -0.016 \\
\hline
\end{tabular}

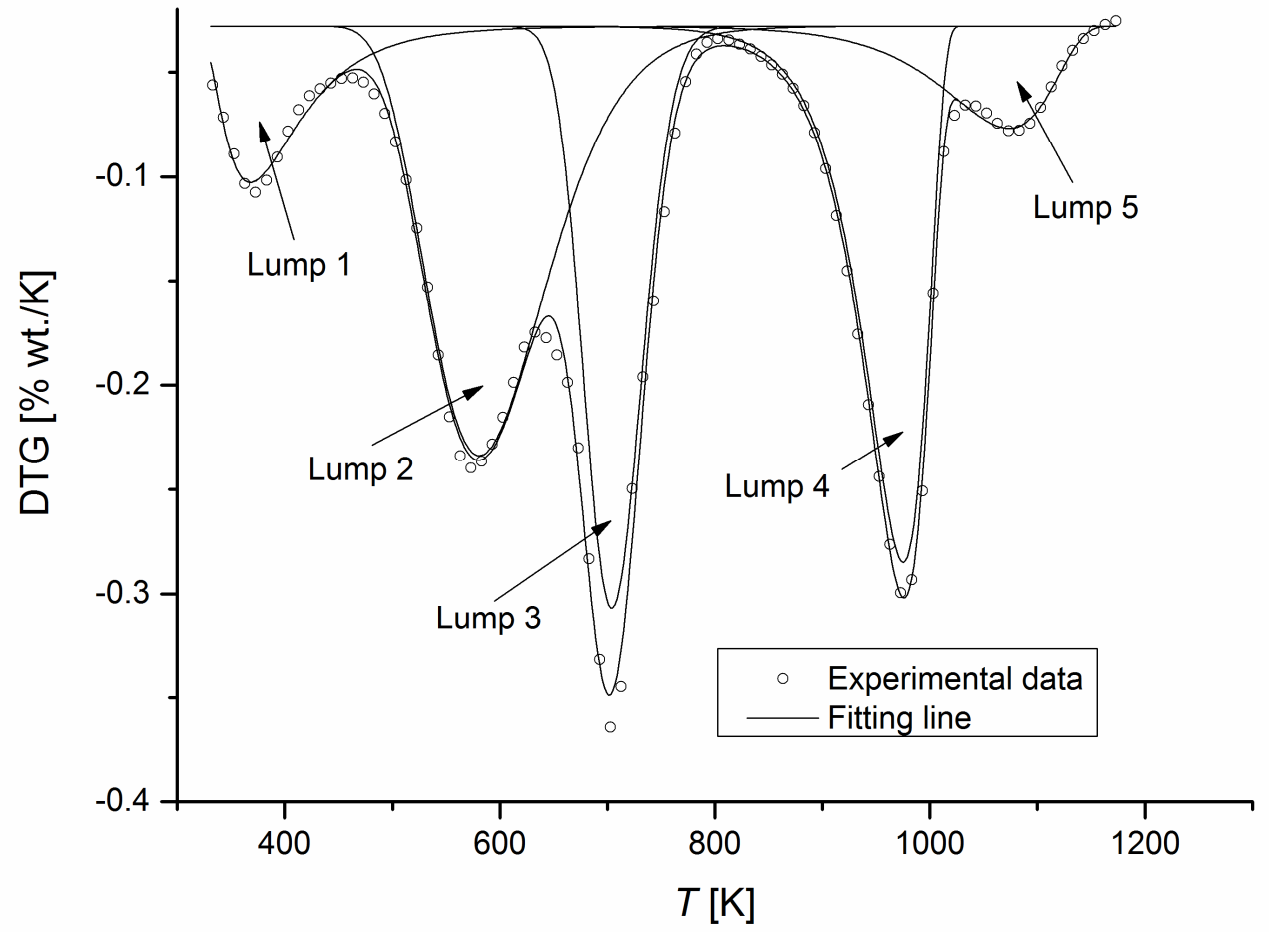

Fig. 4. Deconvolution of the DTG curve for the SS with lime 
Friedman and Ozawa-Flynn-Wall's analysis are good methods allowing in an objective way to recognize if the process can be described by a single or multiple reactions. If the activation energy and pre-exponential factor are constant as a function of conversion degree one can state that we have a single reaction, otherwise one can conclude that many reactions occur. The values of the starting parameters can be estimated from experiment carried out at different heating rates. Friedman analysis is based on the differential form of kinetic equation (2) - DTG curve

$$
\ln \left(\beta \frac{\mathrm{d} \alpha}{\mathrm{d} T}\right)=\ln \left(k_{0}\right)-\frac{E}{\mathrm{R} \cdot T}+\ln [f(x)]
$$

while in the Ozawa-Flynn-Wall analysis the integrated form of the differential equation (2) - TG curve is used:

$$
\log \beta=\left[\log \left(\frac{k_{0} \cdot E}{\mathrm{R}}\right)-\log [g(\alpha)]-2.315\right]-0.457 \frac{E}{\mathrm{R} \cdot T}
$$

where $f(\alpha)$ is differential form of the kinetic equation for the reaction of $n$-th order $(1-\alpha)^{n}$ and $g(\alpha)$ is integrated form of kinetic equation for the reaction of $n$-th order $1 /((n-1) \cdot(1-\alpha))^{n-1}$.

For the both SS the Freiedman's and the Ozawa-Flynn-Wall's analyses were performed. Figure 5 and Table 3 present results of the Friedmann's analysis for the SS without lime. The results of the Ozawa-Flynn-Wall's analysis for the SS with lime are shown in Figure 6 and in Table 4.

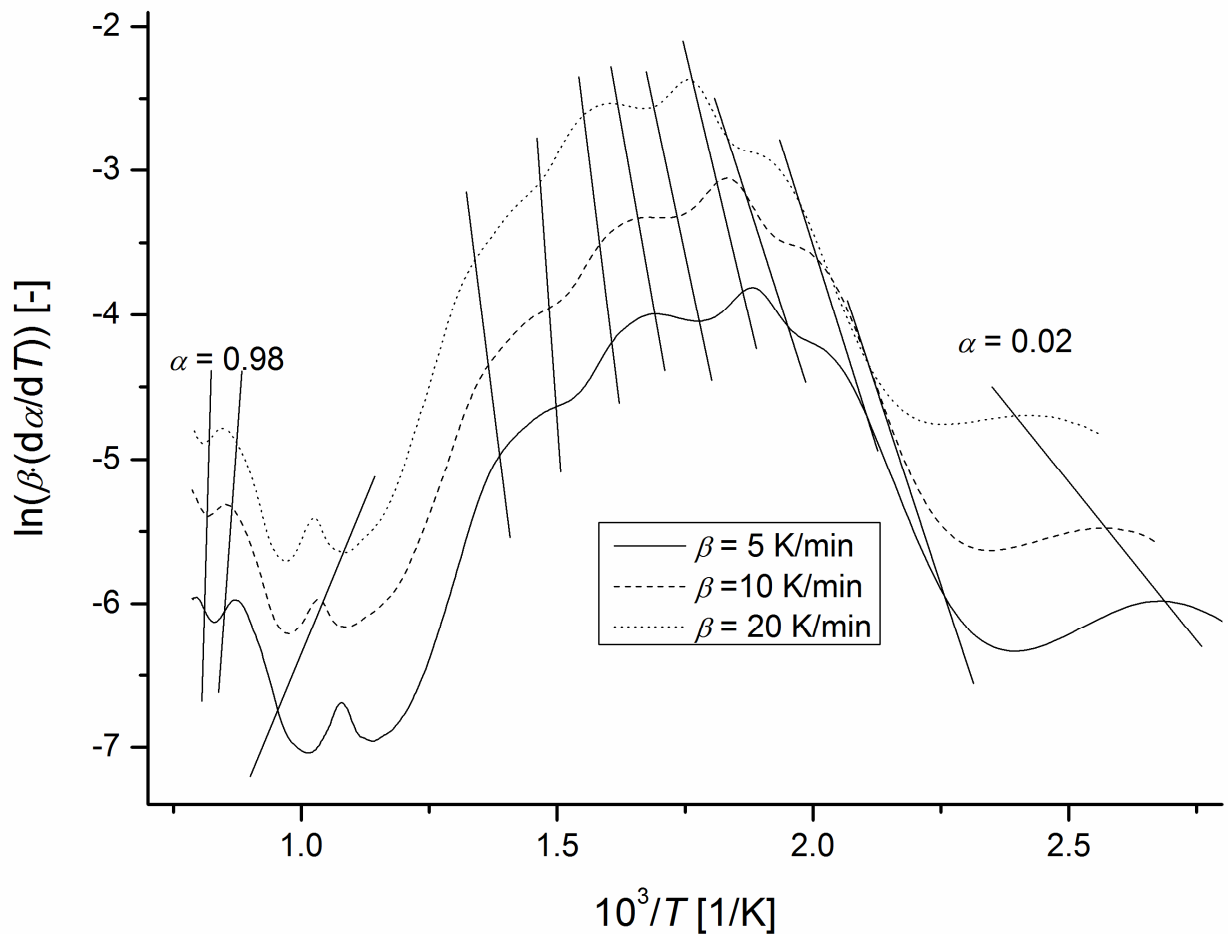

Fig. 5. Friedman's analysis for the SS without liming 
The numerical results of Friedman's analysis for the SS without lime

\begin{tabular}{|c|c|c|}
\hline $\boldsymbol{\alpha}[-]$ & $\boldsymbol{E}[\mathbf{k J} / \mathbf{m o l}]$ & $\log \boldsymbol{k}_{\mathbf{0}}[-]$ \\
\hline 0.02 & $44 \pm 11$ & 1.62 \\
\hline 0.05 & $74.1 \pm 4.1$ & 4.46 \\
\hline 0.10 & $96 \pm 19$ & 6.74 \\
\hline 0.20 & $93 \pm 17$ & 6.04 \\
\hline 0.30 & $117 \pm 26$ & 8.11 \\
\hline 0.40 & $138 \pm 32$ & 9.47 \\
\hline 0.50 & $165 \pm 25$ & 11.30 \\
\hline 0.60 & $231 \pm 13$ & 16.18 \\
\hline 0.7 & $427 \pm 114$ & 30.07 \\
\hline 0.8 & $247 \pm 584$ & 14.56 \\
\hline 0.9 & $-80 \pm 30$ & -7.62 \\
\hline 0.95 & $-356 \pm 328$ & -18.90 \\
\hline 0.98 & $-1000 \pm 701$ & -44.95 \\
\hline & & \\
\hline
\end{tabular}

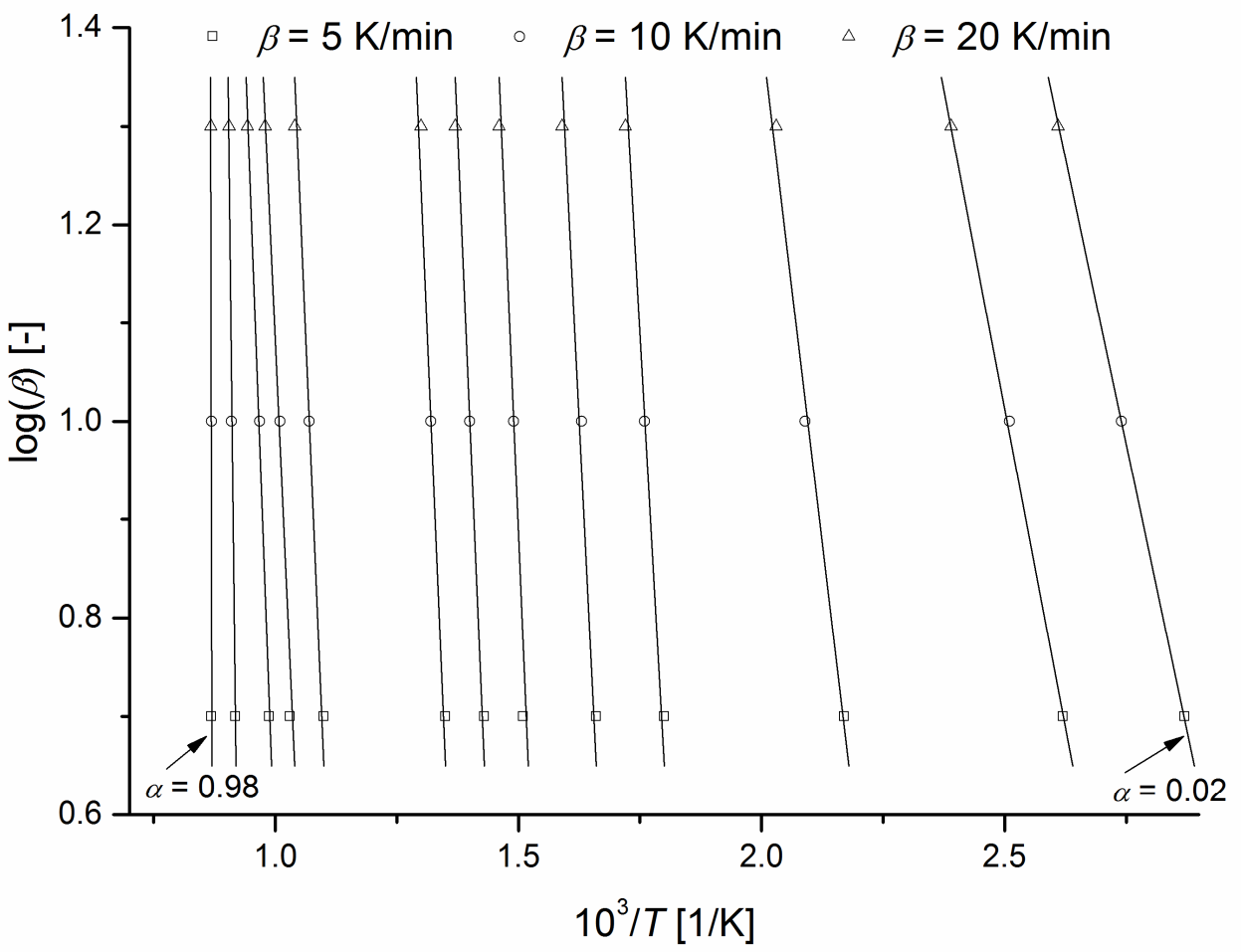

Fig. 6. Ozawa-Flynn-Wall's analysis of the SS with lime

It is worth to notice that the employed methods are very sensitive both for low and high conversion degree in particular when the pyrolysis object is not a single pure substance but so complex substance as the sewage sludge. Therefore the values of activation energy and pre-exponential factors for the conversion degree above $\alpha=0.9$ were not accepted and not taken into account. 
The numerical results of Ozawa-Flynn-Wall's analysis for the SS with liming

\begin{tabular}{|c|c|c|}
\hline $\boldsymbol{\alpha}[-]$ & $\boldsymbol{E}[\mathbf{k J} / \mathbf{m o l}]$ & $\log \boldsymbol{k}_{\boldsymbol{0}}[-]$ \\
\hline 0.02 & $41.3 \pm 1.7$ & 2.08 \\
\hline 0.05 & $43.52 \pm 0.73$ & 2.18 \\
\hline 0.10 & $72.1 \pm 3.5$ & 4.75 \\
\hline 0.20 & $146.8 \pm 8.5$ & 10.79 \\
\hline 0.30 & $175.2 \pm 4.0$ & 12.40 \\
\hline 0.40 & $205.7 \pm 9.7$ & 13.62 \\
\hline 0.50 & $199.49 \pm 0.94$ & 12.32 \\
\hline 0.60 & $200.1 \pm 5.9$ & 11.67 \\
\hline 0.7 & $214.3 \pm 9.6$ & 9.76 \\
\hline 0.8 & $195.8 \pm 3.6$ & 8.13 \\
\hline 0.9 & $250 \pm 28$ & 10.65 \\
\hline 0.95 & $808 \pm 67$ & 37.05 \\
\hline 0.98 & $6498 \pm 1694$ & 293.06 \\
\hline & & \\
\hline
\end{tabular}

For the final estimation of kinetic parameters the non-linear regression was employed. The parameters of the model of $N$ co-current independent reactions:

$$
\begin{aligned}
& A_{1} \stackrel{k_{1}}{\rightarrow} s_{1} B_{1}+\left(1-s_{1}\right) G_{1} \\
& A_{2} \stackrel{k_{2}}{\rightarrow} s_{2} B_{2}+\left(1-s_{2}\right) G_{2} \\
& \vdots \\
& A_{N} \stackrel{k_{N}}{\rightarrow} s_{N} B_{N}+\left(1-s_{N}\right) G_{N}
\end{aligned}
$$

where $A_{i}$ is the substrate undergone the $i$-th reaction, $B_{i}$ solid product of this reaction and $G_{i}$ gaseous product and stoichiometric coefficient $s_{i}$ denotes the ratio of solid product to the mass of reacted substrate, were calculated from the experimental data either for TG curve by minimizing the following target function:

$$
\min L S Q=\sum_{j=1}^{S} \sum_{k=1}^{n}\left(m \exp _{j, k}-m c a l_{j, k}\right)^{2}
$$

or for the differential form (DTG curve)

$$
\begin{aligned}
\min L S Q & =\sum_{j=1}^{S} f_{j} \sum_{k=1}^{n}\left(\frac{\mathrm{d} m \exp _{j, k}}{\mathrm{~d} \tau}-\frac{\mathrm{d} m c a l_{j, k}}{\mathrm{~d} \tau}\right)^{2} \\
f_{i} & =\frac{1}{\max _{k}\left(\frac{\mathrm{d} m \exp _{j, k}}{\mathrm{~d} \tau}\right)^{2}}
\end{aligned}
$$

where $f_{j}$ is normalizing factor taken into account all scans, $S$ is the number of temperature scans, $j$ is scan index, $k$ is the index of measured point, $n$ is the number of measured points in the scan, $m \exp _{j, k}$ is experimental value for the scan $j$-th in measured point $k$-th and $m$ $\mathrm{cal}_{j, k}$ is the calculated value for the scan $j$-th in point $k$-th (solution of the set of differential equations corresponding to the proposed scheme of reactions). 


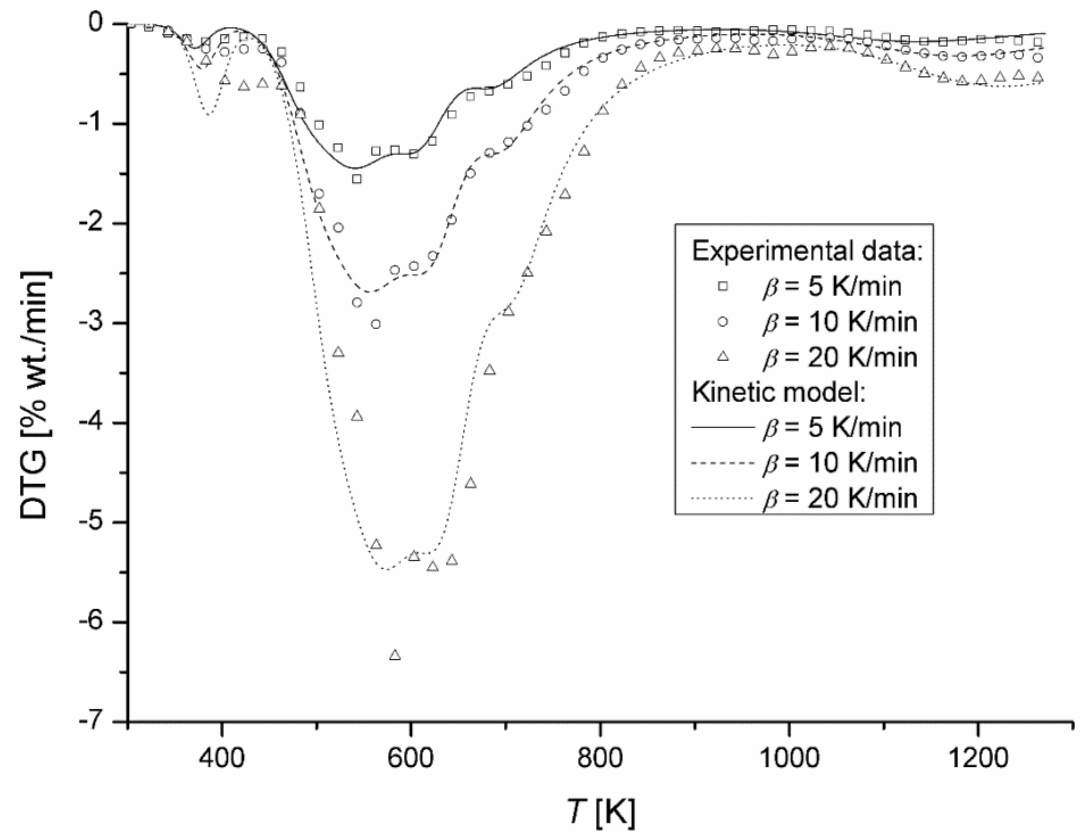

Fig. 7. Experimental and generated TG curves by using the kinetic model involving six parallel $n$-th order reactions for the SS without lime

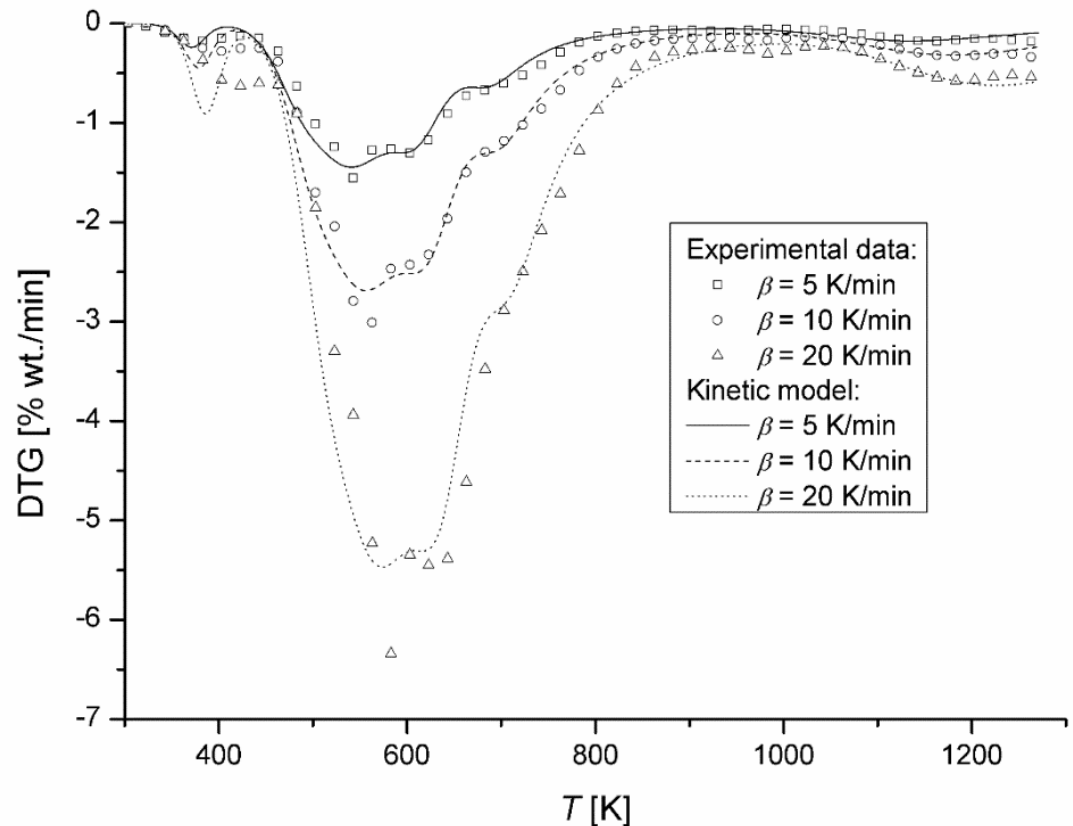

Fig. 8. Experimental and generated DTG curves by using the kinetic model involving six parallel $n$-th order reactions for the SS without lime 
The minimum value of the function ( 5 or 6 ) was searched using Levenberg-Marqurdt optimization procedure. The optimizing parameters were constants in the Arrhenius equation, reaction orders (for the $n$-th order reaction) and the fraction of the reaction in the total mass loss. The calculation was performed by means of Netzsch - Thermokinetics program and then the generated TG and DTG curves were compared with the experimental ones (Figs. 7-10). The fitting is quite good for all the experiments $\left(R^{2}>0.98\right)$. Tables 5 and 6 summarize the model parameters obtained by the non-linear regression for the both SS.

Table 4

Model parameters of the SS without liming pyrolysis

\begin{tabular}{|c|c|c|c|c|c|c|}
\hline Lumps & $\mathbf{1}$ & $\mathbf{2}$ & $\mathbf{3}$ & $\mathbf{4}$ & $\mathbf{5}$ & $\mathbf{6}$ \\
\hline $\log k_{0}[-]$ & 4.18 & 16.29 & 7.98 & 8.01 & 12.57 & 12.02 \\
\hline$E[\mathrm{~kJ} / \mathrm{mol}]$ & 155.6 & 246.4 & 100.3 & 111. & 104.3 & 168.1 \\
\hline Reaction order $(n)[-]$ & 2.57 & 3.56 & 4.99 & 4.39 & 1.69 & 1.85 \\
\hline \multirow{3}{*}{ Total mass loss [\% wt.] } & 0.13 & 0.08 & 0.35 & 0.32 & 0.02 & 0.09 \\
\hline & $(\beta=5 \mathrm{~K} / \mathrm{min})$ & \multicolumn{7}{|c|}{-74.9} \\
\cline { 2 - 7 } & $(\beta=10 \mathrm{~K} / \mathrm{min})$ & \multicolumn{7}{|c|}{-73.4} \\
\cline { 2 - 7 } & $(\beta=20 \mathrm{~K} / \mathrm{min})$ & \multicolumn{7}{|c|}{} \\
\hline
\end{tabular}

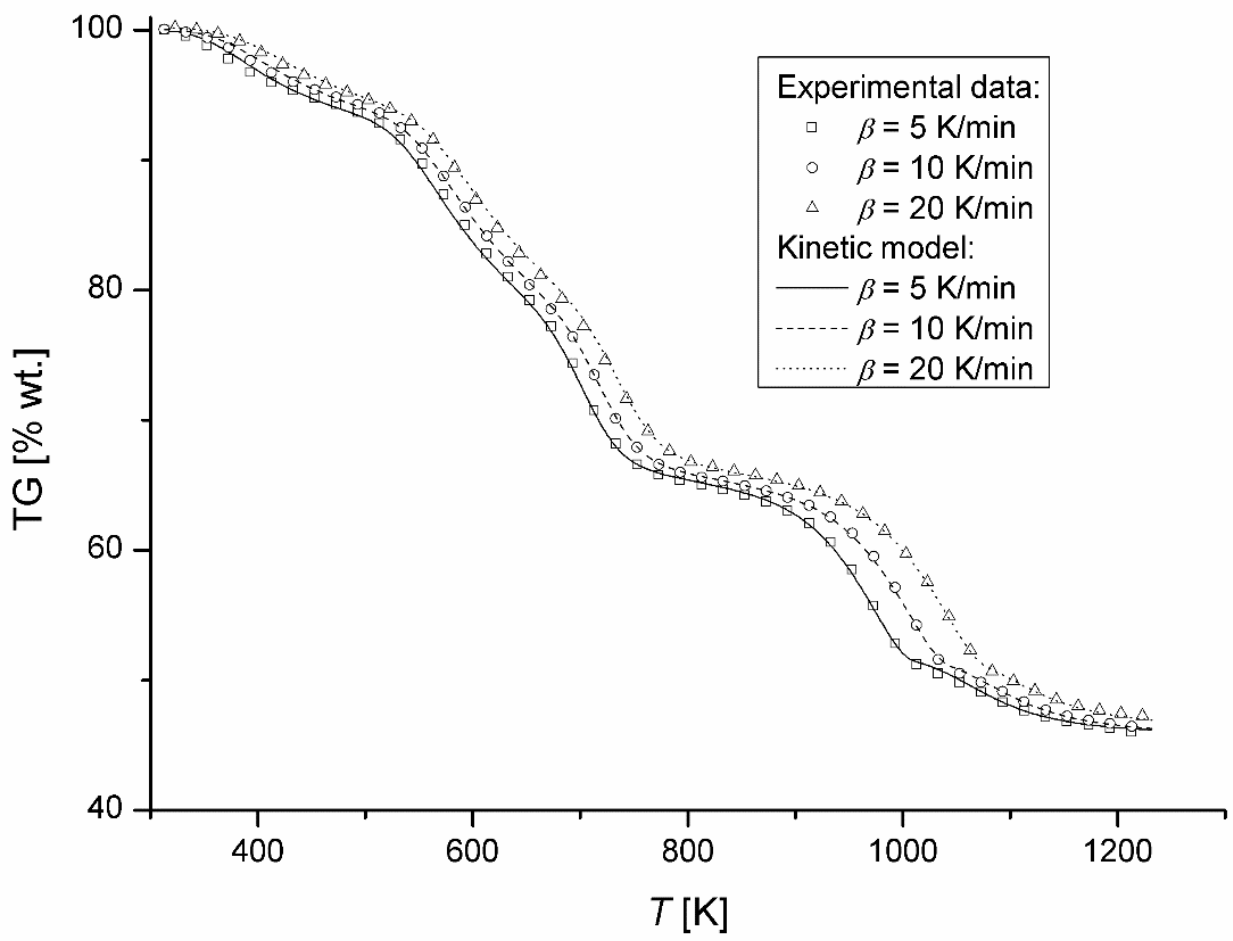

Fig. 9. Experimental and generated TG curves by using the kinetic model involving five parallel $n$-th order reactions for the SS with lime 


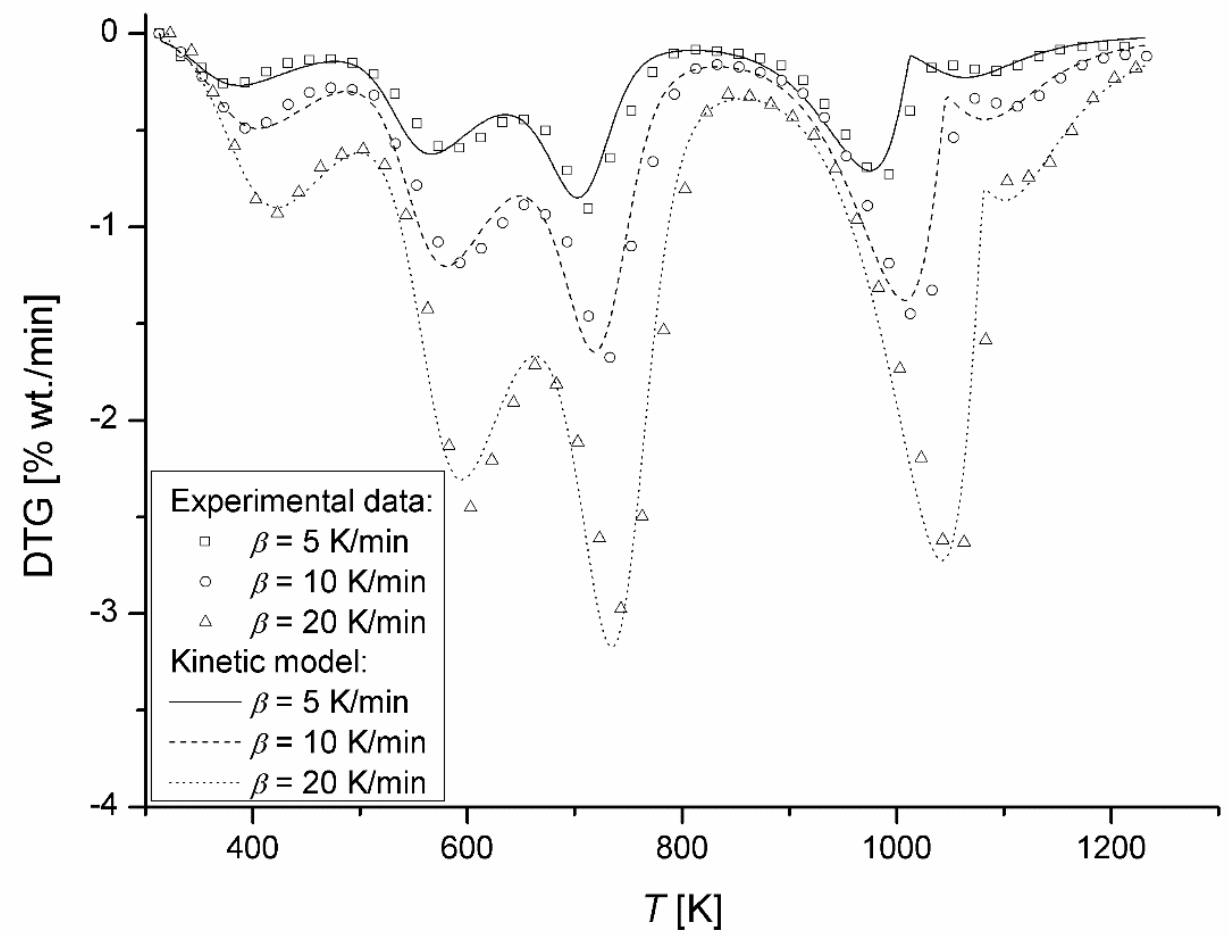

Fig. 10. Experimental and generated DTG curves by using the kinetic model involving five parallel $n$-th order reactions for the SS with lime

Model parameters of the SS with lime pyrolysis

\begin{tabular}{|c|c|c|c|c|c|}
\hline Lumps & $\mathbf{1}$ & $\mathbf{2}$ & $\mathbf{3}$ & $\mathbf{4}$ & $\mathbf{5}$ \\
\hline $\log k_{0}[-]$ & 3.72 & 14.69 & 10.39 & 9.08 & 6.23 \\
\hline$E[\mathrm{~kJ} / \mathrm{mol}]$ & 46.26 & 351.6 & 173.2 & 125.8 & 167.6 \\
\hline Reaction order $(n)[-]$ & 4.99 & 2.81 & 1.41 & 5.32 & 0.56 \\
\hline \multirow{3}{*}{ Total mass loss [\% wt.] } & $\beta=5 \mathrm{~K} / \mathrm{min}$ & \multicolumn{5}{|c|}{-54.29} & 0.09 & 0.17 & 0.34 & 0.23 \\
\cline { 2 - 7 } & $\beta=10 \mathrm{~K} / \mathrm{min}$ & \multicolumn{5}{|c}{-54.03} \\
\cline { 2 - 7 } & $\beta=20 \mathrm{~K} / \mathrm{min}$ & \multicolumn{5}{|l}{} \\
\hline
\end{tabular}

\section{Summary and conclusions}

The kinetics of pyrolysis of two types of sewage sludge with and without addition of lime were investigated in thermo-balance at the three heating rate $\beta=5,10$ and $20 \mathrm{~K} / \mathrm{min}$. The iso-conversion methods of Friedman and Ozawa-Flynn-Wall were employed for analysis of TG results. The deconvolution of DTG curves performed according to Fraser-Suzuki asymmetric profile allowed the identification of number of lumps and their contribution to the overall mass loss. The thermal decomposition of sewage sludge was assumed to proceed according to the scheme of parallel concurrent independent reactions of $n$-th order. For the estimation of kinetic parameters the non-linear regression with 
Levenberg-Marquart optimization procedure was used. The kinetic parameters such as $E$, $k_{0}, n$ and fraction of total mass loss associated with a given reaction were determined. The impact of SS liming revealed in essential differences of pyrolysis products and pyrolysis kinetics of limed sludge and without lime one was highlighted:

- The total mass loss for the SS with lime (ca. $55 \%$ wt.) was smaller than for that without liming (ca. $71 \%$ wt.), what is connected with the higher amount of mineral residue after pyrolysis of the SS with lime. However, the presence of lime in the SS has the great impact at the higher temperature range 823-873 K, which confirmed the previous conclusions on effect of additive [10].

- Calcium oxide acted not only as a stabilizing agent but as a catalyst in the process pyrolysis (the peak at DTG curve at $723 \mathrm{~K}$ ) and mostly during auto-gasification of the pyrolytic char (enhanced reaction rate at $973 \mathrm{~K}$ in DTG curve).

- Comparing the values of the kinetic parameters for the both SS one should be born in mind that each lump can involve many elementary chemical reactions what is reflected in higher reaction order in kinetic equations.

- Moreover, the so called isokinetic or compensation effect $[15,16]$ should be recollected - the values of $E$ and $k_{0}$ are coupled and many pairs of these parameters could generate the same value of kinetic constant.

- The determined kinetic parameters of model for pyrolysis of the both compared SS described very good TG as well as DTG curves and can be used in designing of reactors for the SS pyrolysis, if only residence time and temperature profile inside would be known.

\section{Acknowledgements}

Financial support by the National Centre for Research and Development in Poland within the targeted project entitled "Development of innovative technology for the pyrolysis of sewage sludge from wastewater treatment plant" funded under measure 1.4 of the Operational Program Innovative Economy No WND-POIG.01.04.00-28-025/14 is acknowledged.

\section{References}

[1] Samolada MC, Zabaniotou AA. Waste Manage. 2014;34(2):411-420. DOI: 10.1016/j.wasman.2013.11.003.

[2] Horne PA, Williams PT. Fuel. 1996;75:1051-1059. DOI: 10.1016/0016- 2361(96)00081-6.

[3] Hu X, Gholizadeh M. J Energy Chem. 2019;39:109-143. DOI: 10.1016/j.jechem.2019.01.024.

[4] Čížková A, Juchelková D, Raclavská H. Chem Process Eng. 2011;32(1): 57-68. DOI: 10.2478/v10176-011-0005-7.

[5] Tang S, Tian S, Zheng C, Zhang Z. Energy Fuels. 2017;31:5079-5087. DOI: 10.1021/acs.ebergyfuels.6b03256.

[6] Liu H, Zhang Q, Hu H, Xiao R, Li A, Qiao Y, et al. Fuel. 2014;134:514-520. DOI: 10.1016/j.fuel.2014.06.020.

[7] Liu H, Zhang Q, Hu H, Liu P, Hu X, Li A, et al. Proc Combust Inst. 2015;35(3):2759-2766. DOI: 10.1016/j.proci.2014.06.034.

[8] Urych B, Smolinski A. Energy Fuels. 2016;30:4869-4878. DOI: 10.1021/acs.energyfuels.6b00332.

[9] Hernandez AB, Ferrasse JH., Akkache S, Roche N. Drying Technol. 2015;33(11):1318-1326. DOI: 10.1080/07373937.2015.1036283.

[10] Bedyk T, Nowicki L, Stolarek P, Ledakowicz S. J Residual Sci Technol. 2009;6:3-10. DOI: 1544-8053/09/01 003-08.

[11] Collard FX, Blin J. Renew Sustain Energy Rev. 2014,38:94-608. DOI: 10.1016/j.rser.2014.06.013. 
[12] Shao J, Yan R, Chen H, Yang H, Lee DH. Fuel Processing Technol. 2010;91(9):1113-1118. DOI: 10.1016/j.fuproc.2010.03.023.

[13] Stolarek P, Ledakowicz S. Thermochim Acta. 2005;433:200-208. DOI: 10.1016/j.tca.2005.03.012.

[14] Ranzi E, Dente M, Goldaniga A, Bozzano G, Faravelli T. Progress Energy Combust Sci. 2001;27:99-139. DOI: 10.1016/S0360-1285(00)00013-7.

[15] Brown ME. Handbook of Thermal Analysis and Calorimetry. Vol. 1 Principles and practice. Amsterdam: Elsevier; 1998. ISBN: 044482085X.

[16] Mianowski A. J Therm Anal Cal. 2003;74:953- 973. DOI: 10.1023/B:JTAN.0000011027.59338.54. 